\title{
Low birth weight in Iran based on Iranian Maternal and Neonatal Network (IMaN)
}

\author{
Narjes Khalili ${ }^{1}$, Maziar Moradi-Lakeh*1, Mohammad Heidarzadeh ${ }^{2}$ \\ Received: 18 Nov 2018 \\ Published: 15 Apr 2019
}

Conflicts of Interest: None declared

Funding: None

\section{*This work has been published under CC BY-NC-SA 1.0 license. \\ Copyright $\odot$ Iran University of Medical Sciences}

Cite this article as: Khalili N, Moradi-Lakeh M, Heidarzadeh M. Low birth weight in Iran based on Iranian Maternal and Neonatal Network (IMaN). Med J Islam Repub Iran. 2019 (15 Apr);33:30. https://doi.org/10.47176/mjiri.33.30

\section{Dear editor}

We read, with great interest, a recently published review article entitled " Low birth weight in Iran: Implications from a systematic review of the literature and metaanalysis between 1999 and 2017" by Ebadi et al, which was published in the Medical Journal of the Islamic Republic of Iran (2018; 32 (1): 68-77) (1). We would like to congratulate the authors for this great review article and make some contributions.

Since 2011, to access useful and essential information on maternal and neonatal health indicators and applications for health policy and planning, the "Neonatal Health Office" and the "Bureau of Population, Family, and School Health", in collaboration with other related offices and majority of maternity and neonatal health experts in universities, designed various questionnaires and software to record birth events in hospitals.

At first, this network was implemented as a pilot project in some medical universities. However, since April 2012, all hospitals and birth centers affiliated to medical universities of Iran began to register birth-related data in the Iranian Maternal and Neonatal Network (IMaN). Never- theless, the network has evolved considerably since then.

Iranian Maternal and Neonatal Network (IMaN) is one of the greatest sources of information for monitoring maternal and neonatal health. This network records almost all births (live \& dead), demographics, and maternal and neonatal health information electronically in and out of hospitals across the country. Since 2014, IMaN has registered out of hospital births that have occurred at maternity and child birth facilities, homes, or other places.

In this system, such information as the demographic characteristics of the newborn's mother, relationship between parents, number of parity and gravidity, mode of delivery, abortion history, gestational weeks, mother's medical history, risk factors for pregnancy and childbirth, birth date, and infant's birth characteristics (eg, body weight) are recorded.

Tables 1 and 2 show the classification of infant bodyweight during 3 years. Table 1 includes all births (live \& dead), but Table 2 contains information on live births. As defined by World Health Organization, for low birth weight (up to and including $2499 \mathrm{~g}$ ) (2), the prevalence of LBW rates was $7.3 \%$ in $2014,7.1 \%$ in 2015 , and $7.2 \%$ in

Corresponding author: Dr Maziar Moradi-Lakeh, moradilakeh.m@iums.ac.ir

1. Preventive Medicine and Public Health Research Center, Department of Community Medicine, School of Medicine, Iran University of Medical Sciences, Tehran, Iran

2. Tabriz University of Medical Sciences, Tabriz, Iran

Table 1. Classification of body weight among total births (live \& dead) based on data available in Iranian Maternal and Neonatal Network (20142016)

\begin{tabular}{|c|c|c|c|c|c|c|c|}
\hline Year & Body weight & $\begin{array}{c}\text { Less than } 999 \mathrm{gr} \\
\mathrm{N}(\%)\end{array}$ & $\begin{array}{c}1000-1499 \mathrm{gr} \\
\mathrm{N}(\%)\end{array}$ & $\begin{array}{c}1500-2499 \mathrm{gr} \\
\mathrm{N}(\%)\end{array}$ & $\begin{array}{c}2500-4000 \mathrm{gr} \\
\mathrm{N}(\%)\end{array}$ & $\begin{array}{l}\text { More than } 4000 \text { gr } \\
\mathrm{N}(\%)\end{array}$ & $\begin{array}{c}\text { Total births (live \& dead) } \\
\text { N }(\%)\end{array}$ \\
\hline 2014 & & $11357(0.8)$ & $8734(0.6)$ & $85306(5.9)$ & $1289478(89.7)$ & $42142(2.9)$ & $1437017(100)$ \\
\hline 2015 & & $11900(0.8)$ & $8779(0.6)$ & $86525(5.7)$ & $1357618(89.8)$ & $47403(3.1)$ & $1512225(100)$ \\
\hline 2016 & & $12264(0.8)$ & $8838(0.6)$ & 85985 (5.8) & $1333854(89.7)$ & $46742(3.1)$ & $1487683(100)$ \\
\hline
\end{tabular}

Table 2. Classification of body weight among live births based on data available in Iranian Maternal and Neonatal Network (2014-2016)

\begin{tabular}{|c|c|c|c|c|c|c|c|}
\hline Year & Body weight & $\begin{array}{c}\text { Less than } 999 \mathrm{gr} \\
\mathrm{N}(\%)\end{array}$ & $\begin{array}{c}1000-1499 \mathrm{gr} \\
\mathrm{N}(\%)\end{array}$ & $\begin{array}{c}1500-2499 \mathrm{gr} \\
\mathrm{N}(\%)\end{array}$ & $\begin{array}{c}2500-4000 \mathrm{gr} \\
\mathrm{N}(\%)\end{array}$ & $\begin{array}{c}\text { more than } 4000 \mathrm{gr} \\
\mathrm{N}(\%)\end{array}$ & $\begin{array}{c}\text { Total (live births) } \\
\text { N }(\%)\end{array}$ \\
\hline 2014 & & $6248(0.4)$ & $7528(0.5)$ & $83369(5.8)$ & $1287241(90.2)$ & $42000(2.9)$ & $1426386(100)$ \\
\hline 2015 & & $6747(0.4)$ & $7511(0.5)$ & $84562(5.6)$ & $1355224(90.3)$ & $47263(3.1)$ & $1501307(100)$ \\
\hline 2016 & & $6452(0.4)$ & $7577(0.5)$ & $84010(5.7)$ & $1331689(90.2)$ & $46603(3.2)$ & $1476331(100)$ \\
\hline
\end{tabular}


2016 among total births in Iran. The LBW rates among live births were $6.7 \%$ in $2014,6.5 \%$ in 2015 , and $6.6 \%$ in 2016.

However, in Ebadi et al. study, the prevalence of LBW was $8 \%$ (95\% CI: 7-9) in Iran.

The difference may be due to the lack of studies on the LBW rate in different geographical areas of Iran, high heterogeneity rate, and the quality of included studies in this systematic review (1). Also, the coverage rate of IMaN throughout the country is almost more than $95 \%$.

\section{Conflict of Interests}

The authors declare that they have no competing interests.

\section{References}

1. Ebadi F, Ghashghaee A, Luigi Bragazzi N, Martini M, Sepehrian R, Ghaemmohamadi M, et al. Low birth weight in Iran:implications from a systematic review of the literature and meta-analysis in the period 1999-2017. Med J Islam Repub Iran. 2018(13 Feb);32:13.

2. WHO. International statistical classification of diseases and related health problems, tenth revision, 2nd ed. World Health Organization; 2004 